\title{
A CONCEPÇÃO DE FORMAÇÃO HUMANA NOS CURSOS DE LICENCIATURAS DO INSTITUTO FEDERAL DE EDUCAÇÃO CIÊNCIA E TECNOLOGIA DA PARAÍBA - IFPB
}

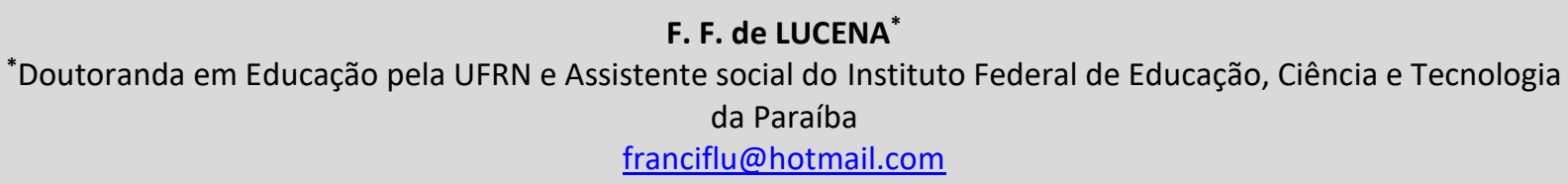

Artigo submetido em dezembro/2016 e aceito em janeiro/2017

DOI: $10.15628 /$ rbept.2016.5443

\section{RESUMO}

O artigo visa analisar o conceito de formação humana presente nos projetos pedagógicos dos cursos de licenciatura em química e matemática ofertados pelo Instituto Federal de Educação, Ciência e Tecnologia da Paraíba- IFPB. Adotaremos o conceito de formação humana presente no pensamento gramsciano, o qual defende a indissociabilidade entre conhecimento histórico, práxis política e formação humana. Trata-se de estudo bibliográfico, onde foram consultados livros, artigos científicos, leis e os projetos pedagógicos dos referido cursos. Contata-se que os conceitos de formação docente e formação humana presentes nos projetos pedagógicos dos referidos cursos apresentam pontos de convergência com o pensamento gramsciano, ao buscarem uma formação omnilateral, privilegiando a interdisciplinaridade e a contextualização dos conhecimentos.

PALAVRAS-CHAVE: Formação humana, Projeto pedagógico, Licenciatura.

\section{THE CONCEPTION OF HUMAN FORMATION IN THE INSTITUTO FEDERAL DE EDUCAÇÃO CIÊNCIA E TECNOLOGIA DA PARAÍBA'S (IFPB) UNDERGRADUATE COURSES}

\begin{abstract}
This article focuses on analysing the concept of human formation that is present in the pedagogical projects of undergraduate courses in chemistry and mathematics offered by the Instituto Federal de Educação, Ciência e Tecnologia da Paraíba- IFPB. We adopted the human formation concept present in Gramsciano thinking, which defends the inseparability between historical knowledge, political praxis and human formation. This is a bibliographic study, which consulted books, scientific articles, laws and
\end{abstract}

pedagogical projects of the previously mentined courses. The concepts of formation of the teaching body and human formation present in the pedagogical projects of the undergraduate courses analysed, demonstrated points of convergence with Gramsciano thinking, in the sense that they are looking for an omnilateral formation, emphasizing the interdisciplinary nature and the contextualization of knowledge.

Keywords: Human Formation, Pedagogic Project, Undergraduate Course. 


\section{APRESENTAÇÃO}

Nesse artigo, buscaremos analisar o conceito de formação humana presente no Plano de Desenvolvimento Institucional do IFPB (PDI 2015-2019), destacando como este está contemplado nos projetos pedagógicos dos cursos de Licenciatura ofertados pelo IFPB.

Tomaremos como objeto de análise os Projetos Pedagógicos dos cursos de Licenciatura em Química do Campus João Pessoa e Licenciatura em Matemática do Campus Cajazeiras. A escolha por tais cursos justifica-se pelo fato de o Curso de Química do Campus João Pessoa ter sido a primeira Licenciatura a ser ofertada pelo IFPB, no ano de 2004. Já o curso de Licenciatura em Matemática do Campus Cajazeiras, por ter sido implantado no ano de 2011, pós processo de Ifetização/interiorização do IFPB, no sertão paraibano.

Para realizarmos a análise, tomaremos como marco teórico o conceito de Formação Humana presente no pensamento de Gramsci, por meio de um dos seus interlocutores no Brasil, o professor Carlos Eduardo Vieira (1999), da Universidade Federal do Paraná).

\section{BREVE HISTÓRICO DO IFPB}

As Escolas de Aprendizes Artífices (EAA) foram instituídas no Brasil, em 1909, pelo Decreto n.7566/1909,com o propósito de "habilitar os filhos dos desfavorecidos da sorte com o indispensável preparo técnico e intelectual, como fazê-los adquirir hábitos de trabalho profícuo, que os afastará da ociosidade, escola do vício e do crime" (QUELUZ, 2000, p. 32).

Essas escolas eram subordinadas ao Ministério dos Negócios da Agricultura e destinavamse ao ensino profissional primário gratuito, tendo sido difundidas pelos estados da Federação em número de vinte, com o objetivo de espalhar por todo o território nacional o ensino das artes e ofícios, especificamente aos menores abandonados e órfãos, com a finalidade de atender à realidade econômica local em consonância com as transformações da sociedade brasileira, sendo subordinadas administrativamente a uma autoridade do poder central que mantinha diretrizes pedagógicas comum a todas.

O atual Instituto Federal de Educação Ciência e Tecnologia da Paraíba (IFPB) foi uma das EAA criada pelo Decreto no 7.586, de 23 de setembro, no governo do Presidente da República Nilo Peçanha. De 1909 aos dias atuais, essa instituição recebeu diferentes denominações, a saber: Escola de Aprendizes Artífices da Paraíba, de 1909 a 1937; Liceu Industrial de João Pessoa, de 1937 a 1961; Escola Industrial "Coriolano de Medeiros" ou Escola Industrial Federal da Paraíba, de 1961 a 1967; Escola Técnica Federal da Paraíba, de 1967 a 1999; Centro Federal de Educação Tecnológica da Paraíba, de 1999 a 2008 e, finalmente, IFPB, de 2008 aos dias atuais.

A Escola de Aprendizes Artífices da Paraíba começou a funcionar com os cursos de Alfaiataria, Marcenaria, Serralharia, Encadernação e Sapataria. Os cursos eram realizados em 
conjunto com o curso Primário e destinados ao atendimento daqueles que necessitavam de uma profissão e não podiam pagar pelo ensino. Essa fase caracterizou-se pela oferta de cursos relacionados à manufatura.

Em 1937, por meio da Lei n. 378 a EAA transformava-se em Liceu Industrial, sendo o primeiro a tratar, especificamente, de Ensino Técnico, Profissional e Industrial, ofertando, desse modo, o Ginásio Industrial, representando uma segunda fase da história econômica brasileira.

Com a Reforma Capanema, em 1942, houve várias mudanças importantes na educação brasileira, inclusive para o Ensino Profissional, que vivenciou diversas transformações como forma de adequação ao momento sócio-histórico e cultural do país. Essas transformações, conforme Manfredi (2000, p. 99), deram as seguintes características ao ensino secundário e demais ramos do ensino:

\begin{abstract}
O ensino secundário (Decreto-Lei 4.244, de 9 de abril de 1942) tinha por objetivo formar os dirigentes, pelo próprio ensino ministrado e pela preparação para o superior. Os demais ramos do ensino médio tinham a finalidade de formar uma força de trabalho específica para os setores da produção e da burocracia: o ensino agrícola para o setor primário; o ensino industrial para o setor secundário; o ensino comercial para o setor terciário; o ensino normal para a formação de professores para o ensino primário. Cada ramo de ensino estava dividido em dois ciclos, o primeiro propedêutico ao segundo.
\end{abstract}

Nesses termos, o Decreto no 4.127/42 transformou o Liceu Industrial em Escola Industrial de João Pessoa, também conhecida pela denominação de Escola Industrial Federal de João Pessoa até 1959.

No contexto, surgiu a Escola Agrotécnica Federal (EAF), da cidade de Sousa, baseada no Decreto 9.613, de 20 de agosto de 1946, na zona urbana, sendo autorizada a funcionar a partir de 09 de agosto de 1955.

Em 1960, a já então Escola Técnica Federal da Paraíba (ETF/PB) transferiu-se da Rua João da Mata para um prédio construído na Avenida 10 de maio, número 720 , atualmente denominado IFPB/Campus de João Pessoa. Naquele contexto, a Escola Técnica Federal da Paraíba iniciava a implantação de cursos técnicos em nível de 2 o Grau (atualmente denominado Ensino Médio), por meio dos Cursos Técnicos em Construção de Máquinas e Motores e o de Pontes e Estradas. A oferta dos referidos Cursos tinha a finalidade de atender a demanda da intensificação do processo de modernização industrial do país.

Nesse contexto, a instituição caracterizava-se pela oferta quase exclusiva de cursos técnicos de nível médio com o objetivo de atender ao novo modelo econômico desencadeado pelo propalado "milagre econômico", especialmente na década de 1970.

Em todas as fases, manufatureira, industrial e desenvolvimentista, as Escolas sempre procuravam articular a formação profissional com a educação básica, por meio do ensino fundamental ou médio. 
Ainda como Escola Técnica Federal da Paraíba, no ano de 1995, a Instituição interiorizou suas atividades por meio da instalação da Unidade de Ensino Descentralizada de Cajazeiras (UNED).

Transformada, em 1999, no Centro Federal de Educação Tecnológica da Paraíba (CEFETPB), a Instituição experimentou um fértil processo de expansão e diversificação de suas atividades, oferecendo à sociedade paraibana e brasileira, todos os níveis de educação, desde a educação básica à educação superior (cursos de graduação na área tecnológica), intensificando também as atividades de pesquisa e extensão.

Como Centro Federal de Educação Tecnológica da Paraíba, ocorreu em 2007 a implantação da Unidade de Ensino Descentralizada de Campina Grande (UNED-CG) e a criação do Núcleo de Ensino de Pesca, no município de Cabedelo.

Também em 2007, o Ministério da Educação publicou o Plano de Desenvolvimento de Educação Pública (PDE), apresentando concepções e metas acerca da educação nacional por meio do Decreto no 6.085, estabelecendo diretrizes para os processos de integração de instituições federais de educação tecnológica, visando à constituição de uma rede de institutos federais.

Assim, com base no PDE, em 12 de março de 2008¹, o CEFET/PB e a Escola Agrotécnica Federal de Sousa protocolaram, no Ministério da Educação, proposta de implantação do Instituto Federal de Educação, Ciência e Tecnologia da Paraíba. A proposta, em resposta à Chamada pública MEC/SETEC n. 002/2007 foi selecionada conforme Portaria n. 116, de 31 de março de 2008. Ao final de 2008, a Lei no 11.892 instituiu a Rede Federal de Educação, Ciência e Tecnologia, o que possibilitou a implantação do Instituto Federal de Educação, Ciência e Tecnologia da Paraíba (IFPB).

Com o advento da Lei 11.892/2008, que criou os Institutos Federais de Educação, Ciência e Tecnologia que, de acordo com o Art 2ㅇ da referida lei, os Institutos Federais:

[...] são instituições de educação superior, básica e profissional, pluricurriculares e multicampi, especializados na oferta de educação profissional e tecnológica nas diferentes modalidades de ensino, com base na conjugação de conhecimentos técnicos e tecnológicos com as suas práticas pedagógicas (BRASIL, 2008).

De acordo como o processo de Expansão da Rede Federal de Educação Profissional e visando atender aos objetivos propostos pela referida lei, o IFPB implantou, no ano de 2010, 05 (cinco) Campi no estado da Paraíba, contemplando cidades consideradas polos regionais de desenvolvimento, como Picuí, Monteiro, Princesa Isabel, Patos e Cabedelo - essas ações de expansão do IFPB são conhecidas como Fase II da expansão. Esses novos campi, associados aos Campi de Cajazeiras, Campina Grande, João Pessoa e Sousa (Escola Agrotécnica, que foi incorporada ao antigo CEFET), passaram a constituir a nova estrutura organizacional do IFPB.

\footnotetext{
${ }^{1}$ Fonte: DTI (Departamento de Tecnologia da Informação sobre o IFPB) acesso em dezembro de 2015.
} 
No ano de 2014, o Instituto Federal da Paraíba, em sintonia com o mercado de trabalho e com a expansão da Rede Federal de Educação Profissional- Fase III- implantou mais 06 (seis) novos Campi nas cidades de Guarabira, Itaporanga, Itabaiana, Catolé do Rocha, Santa Rita e Esperança, ampliando as oportunidades educacionais da população paraibana.

Ainda dentro do processo de expansão, no ano de 2016, encontram-se em fase de implantação os campi de Areia, Mangabeira, Pedras de Fogo, Santa Luzia e Soledade. Assim, junto àqueles já existentes, levando-se em consideração que cada unidade abrange, de forma razoável, um raio 50 quilômetros, promove a interiorização da educação no território paraibano, contribuindo para o alcance da missão institucional de fazer desenvolver a região a partir das potencialidades locais.

As novas unidades educacionais do IFPB oferecem à sociedade, paraibana e brasileira, cursos técnicos de nível médio (integrado e subsequente), cursos superiores de tecnologia, bacharelado e licenciatura, na forma presencial e a Distância (EaD), todos em consonância com a linha programática e princípios doutrinários firmados na Lei de Diretrizes e Bases da Educação Nacional (LDB/EN) e normas dela decorrentes.

Atualmente, o IFPB oferta 118 cursos, sendo 77 técnicos de nível médio (integrados e subsequentes), 37 superiores (tecnólogos, bacharelado, engenharia e licenciaturas), 3 cursos de especialização e 1 mestrado, atendendo a 11.360 alunos em todo o estado da Paraíba (IFPB, 2016).

\section{ANÁLISE E DISCUSSÕES}

Sobre os motivos que levaram à expansão dos cursos de licenciatura dos Institutos Federais, Lima e Silva (2011) indicam que a principal razão defendida para essa iniciativa se relaciona à escassez de professores no Brasil. Moura (2010) ressalta que, no Brasil, há demanda por formação de professores e que os IFs assumem papel estratégico na formação docente, pois há uma carência de 235.000 (duzentos e trinta e cinco mil) professores para o Ensino Médio no Brasil, particularmente em Física, Química, Matemática e Biologia, sendo 55.000 (cinquenta e cinco mil) só para a disciplina de Física (BRASIL, 2007). Além disso, Gatti e Barreto (2009) apontam que 735.628 (setecentos e trinta e cinco mil, seiscentos e vinte e oito) professores que atuam na educação brasileira não possuem nível superior de escolarização.

Segundo Moura (2010), citando dados do INEP, no Brasil, as escolas públicas que oferecem ensino fundamental e médio enfrentam um déficit de mais de 235 mil professores, principalmente nas disciplinas de Física, Matemática, Química e Biologia, sendo que, na área de Física, ao compararmos a demanda e o número de docentes formados por ano, podemos concluir que, se mantivermos os números atuais, a demanda somente será suprida em 80 anos. 
Diante do problema da escassez de professores da área das ciências da natureza, a rede federal de educação profissional e tecnológica foi impelida a ofertar cursos de licenciaturas nas áreas prioritárias.

Com a criação dos Institutos Federais de Educação Ciência e Tecnologia, pela Lei no 11.892, o estado brasileiro vem tentando suprir esta demanda de professores. Os Institutos Federais têm, entre outras, a finalidade, conforme estabelece o seu Art. 70, inciso VI, letra b, de ministrar "Cursos de licenciatura, bem como programas especiais de formação pedagógica, com vistas na formação de professores para a educação básica, sobretudo nas áreas de ciências e matemática" (BRASIL, 2008).

Segundo o art 8ㅇ da mesma lei, todos os IFs devem garantir o mínimo de $20 \%$ de suas vagas para cursos voltados para a formação de professores (BRASIL, 2008). Assim, ampliando o seu leque de possibilidades educacionais o IFPB passou a atuar na formação de professores, em observância aos princípios e objetivos da Política Nacional de Formação de Profissionais do Magistério da Educação Básica, estabelecidos no Decreto 8.752, de 09 de maio de 2016.

Visando a atender o que a Lei $11.892 / 2008$ e o Decreto 8.752/2016 preconizam, o IFPB, ao elaborar o seu Plano de Desenvolvimento Institucional (2015-2019) e o Projeto Pedagógico Institucional (PPI), sinalizam os Princípios Filosóficos e Teóricos Metodológicos que norteiam as práticas no âmbito do IFPB.

O Plano de Desenvolvimento Institucional do IFPB está fundamentado no exercício de uma gestão democrática e descentralizada, na autonomia administrativa, financeira e didáticocientífica, na defesa do ensino de qualidade, público e gratuito, na indissociabilidade entre ensino, pesquisa e extensão interligados com seu compromisso social, no desenvolvimento sustentável, na igualdade de condições de acesso e permanência do discente na Instituição (IFPB, 2014).

Nesse documento, a educação "é entendida enquanto uma prática sócio-política realizada no âmbito das relações sócio histórico-culturais", cujo papel deve ser "formar profissionais que pensem e reflitam sobre o mundo", situando-o dentro do seu contexto social e assumindo o seu papel de protagonista de uma nova sociedade. Essa formação requer o reconhecimento de valores e princípios que contribuam para práticas integradoras, emancipatórias e inclusivas (IFPB, 2014).

Pelo exposto, visa a formar um indivíduo consciente do seu papel histórico, na construção da sociedade e utilização de novas tecnologias do conhecimento de forma crítica e reflexiva, ou seja, conhecendo a tecnologia, sua relação com a ciência, o binômio tecnologia e progresso e suas repercussões nas relações sociais (IFPB, 2014).

Portanto, o conceito de educação que está contido no PDI-IFPB encontra-se fundamentado no pensamento gramsciano, quando o mesmo, contrapondo-se às interpretações naturalistas e positivistas do homem e da história, definiu o homem "como espírito, isto é, criação histórica e não natural", afirmando, assim, a possibilidade de o homem tornar-se sujeito de sua história e do seu papel no processo de transformação da realidade e da história (GRAMSCI, 1972, p.24). 
Para Gramsci, a formação do indivíduo tem uma função estratégica na implementação do projeto de classe, na perspectiva de construção de sua hegemonia. Portanto, a vantagem de adotarmos uma postura historicista diante da análise da realidade possibilita-nos compreender os problemas dentro de um contexto histórico, que é determinante do que se pensou e de como as coisas foram pensadas (VIEIRA, 1999, p.54).

O IFPB tem promovido a formação de professores por meio da oferta de cursos de Licenciatura em Matemática e Química, ou por outras ações, como cursos de especialização e aperfeiçoamento para professores, projetos de pesquisa e extensão, envolvendo profissionais da educação, programa de apoio à docência (PARFOR).

Conforme orientação do PDI (2015-2019), a organização curricular dos cursos de licenciatura do IFPB, nas formas presencial e a distância, deverão orientar-se pelas seguintes diretrizes:

- a formação para o humano, ou seja, a consolidação da educação omnilateral;

- a docência como base da formação profissional de todos aqueles que se dedicam ao estudo do trabalho pedagógico;

- o trabalho pedagógico como foco formativo;

- a sólida formação teórica em todas as atividades curriculares - nos conteúdos específicos a serem ensinados pela escola básica e nos conteúdos especificamente pedagógicos;

- a ampla formação cultural;

- a criação de experiências curriculares que permitam o contato dos alunos com a realidade da escola básica, desde o início do curso;

- incorporação da pesquisa como princípio de formação;

- a possibilidade de vivência, pelos alunos, de formas de gestão democrática;

- desenvolvimento do compromisso social e político da docência;

- a reflexão sobre a formação do professor e sobre suas condições de trabalho (IFPB, 2014).

Ao analisarmos o Projeto Político Pedagógico do Curso de Licenciatura em Química do Campus João Pessoa (2010), constata-se que a proposta de formação docente envolve questões relacionadas com responsabilidade social, inclusão digital e social, interdisciplinaridade e transdisciplinaridade, ética profissional, dentre outros. Dentre as diretrizes pedagógicas delineadas, encontra-se a responsabilidade da integração entre ciência, tecnologia, cultura e conhecimentos específicos fundamentada na indissociabilidade do ensino, da pesquisa e da extensão, cuja expressão do fazer pedagógico possibilite formar profissionais com visão crítica e capacidade criativa que o capacite a ser um transformador da sua sociedade (IFPB, 2010, p.10). No que concerne ao conceito de formação humana, verifica-se que essa dimensão não foi contemplada na elaboração do Projeto Pedagógico do Curso de Química. 
No que tange ao Projeto Político Pedagógico do Curso de Licenciatura em Matemática do Campus Cajazeiras, o mesmo sinaliza que a formação docente deve contemplar, como uma de suas dimensões centrais, conhecimentos da esfera trabalho e educação de uma forma geral e, especificamente, da educação profissional. De acordo com o referido projeto, o curso deve:

Garantir uma formação que contemple simultaneamente as demandas sociais, econômicas e culturais diversificadas e a formar um professor destinado a atuar na Educação Básica e/ou Profissional, garantindo a construção de sólidas bases profissionais para uma formação docente sintonizada com a flexibilidade exigida pela sociedade atual, numa perspectiva integradora, dialógica e emancipatória, comprometida com a inclusão social (IFPB, 2011, p.21).

Quanto ao conceito de Formação Humana apresentado no Projeto do Curso de Matemática, percebe-se que o mesmo sinaliza o compromisso social do IFPB com o desenvolvimento pleno dos seus alunos, seu preparo para o exercício da cidadania e sua qualificação para o trabalho dentro do contexto da Educação Profissional e Tecnológica, ofertada com qualidade, preparando-os para serem agentes transformadores da sua realidade social (IFPB, 2011, p. 23).

Portanto, os conceitos de formação docente e formação humana que embasam os projetos pedagógicos dos cursos de Licenciatura em Química e Matemática ofertados pelo IFPB mantêm uma estreita relação como o pensamento gramsciano. Para Vieira (1999), no pensamento gramsciano, existe "uma indissociável vinculação entre conhecimento histórico, práxis política, luta cultural e formação humana e processos de formação humana".

Gramsci concebia a cultura como "único bem universal", ainda que o seu acesso estivesse restrito na sociedade de classes. Para ele, o acesso à cultura promoveria um novo "modo de ser, que determinaria uma nova forma de consciência". A difusão da cultura visava a promover a iniciativa e a autonomia intelectual da classe operária. Portanto, a cultura, a sua organização e o seu processo de difusão são compreendidos como parte do processo de afirmação política da classe operária.

Uma questão que se destaca na análise gramsciana da cultura é a íntima relação entre a cultura e a estrutura social. Para ele, a cultura é materializada em uma rede de associações, podendo e devendo ser compreendida estruturalmente. Contudo, é necessário sempre ter presente que homens e classes sociais se movimentam nessas estruturas, lutando pelos seus projetos. Para Gramsci a cultura

É composta de múltiplas ambiências: a família, a religião, a língua, a classe social, a religião, a escola, o trabalho, enfim, na expressão de Gramsci, as diversas sociedades que produzem os horizontes culturais de formação do indivíduo em sociedade. 
Pelo exposto, percebe-se que Gramsci compreendia os operários e camponeses não mais como passivos e receptores de cultura, mas sim, como críticos e produtores de conhecimento. 0 autor deu continuidade à reflexão que se ampliou sobre o conceito de cultura, ao incluir no seu interior a questão do trabalho, dos processos técnicos e das funções produtivas, próprios do industrialismo, em relação à apropriação privada da riqueza no âmbito do capitalismo. Para ele, "todos são cultos porque participam da vida, confrontam-se com a natureza e as sociedades defrontam-se com problemas reais e produzem soluções práticas" (apud VIEIRA, 1999, p. 59).

A partir de 1934, Gramsci dedica-se com mais afinco a escrever sobre seu novo conceito de cultura, sendo as questões culturais encontradas em destaque nos Quaderni. A partir de então, Gramsci passa a afirmar o conceito de cultura em duas direções: de um lado, a cultura significa modo de pensar e sentir a realidade por parte de uma civilização e, em segundo lugar, é concebida como projeto de formação do indivíduo, como ideal educativo a ser transmitido para novas gerações. Em síntese, cultura significa um modo de viver que se reproduz por meio de um projeto de formação.

\section{CONSIDERAÇÕES FINAIS}

Sabemos que, tradicionalmente, os cursos de licenciaturas eram promovidos pelas universidades e que a oferta de tais cursos pelos IFs representa um grande desafio para essas instituições, cujo histórico de atuação está diretamente relacionado à formação de profissionais para áreas técnicas. Faz-se necessário enfatizar que esse desafio imposto a essa nova institucionalidade pode gerar uma crise de identidade de tais instituições, uma vez que elas devem formular projetos educativos para atender alunos de diversas faixas etárias e níveis de ensino.

Ao analisarmos a legislação que fundamenta a oferta de cursos de licenciatura pelos IFs, percebe-se que essa iniciativa decorre da preocupação em suprir a escassez de professores para atuarem na educação básica, especificamente nas disciplinas de química, física, matemática e biologia. No entanto, a complexidade exigida na formação de professores não será atendida se os cursos de licenciaturas forem resultados apenas da preocupação do cumprimento de uma normatização. Ao se criarem cursos apenas com a finalidade de atingir uma meta quantitativa, corre-se o risco de uma precarização das licenciaturas.

$\mathrm{Na}$ análise dos projetos pedagógicos dos cursos de química e matemática ofertados pelo IFPB, contata-se que os conceitos de formação docente e formação humana apresentam pontos de convergência com o pensamento gramsciano, ao buscarem uma formação omnilateral, privilegiando a interdisciplinaridade e a contextualização dos conhecimentos, dirigindo o ensino para a construção do conhecimento e o desenvolvimento das competências necessárias para uma atuação no mundo de forma reflexiva, cooperativa e solidária. Destaca-se também a importância atribuída ao aspecto cultural no processo formativo e sua contribuição para formação de profissionais críticos, reflexivos e responsáveis pela transformação da realidade social onde estão inseridos. 
Os referidos projetos também sinalizam que as práticas pedagógicas devem estar vinculadas também a um processo reflexivo constante por parte do professor, bem como a uma perspectiva que considere a aprendizagem como um processo dinâmico, resultado das múltiplas relações que se estabelecem entre aquele que aprende (e também ensina) e aquele que ensina ou pretende ensinar (e que igualmente aprende).

No entanto, considera-se como um grande desafio a implementação dos referidos projetos pedagógicos, haja vista que a oferta de cursos de licenciaturas configura-se como algo inovador para o IFPB, o qual, durante muitos anos, ofertou apenas educação profissional de nível médio. Outro fator que deve ser considerado está relacionado às reais condições de infraestrutura para ofertar tais cursos, já que isso exige laboratórios pedagógicos, acervo bibliográfico, contratação de novos professores, capacitação docente e que a grande maioria dos professores que atuam na educação profissional não possuem habilitação para lecionar em cursos de licenciatura.

Nesse sentido, Brzezinski (2002) apresenta a preocupação de que a formação em instituições de educação profissional e tecnológica torne-se tecnicista, devido às suas históricas implantações de políticas que visam à configuração técnica e pragmática de formar o trabalhador para o mundo produtivo.

\section{REFERÊNCIAS}

BRASIL. Lei no 11.892, de 29 de dezembro de 2008. Cria os Institutos Federais de Educação, Ciência e Tecnologia, e dá outras providências. Brasília, 2008.

BRASIL. Decreto 8.752, de 09 de maio de 2016.Dispõe sobre a Política Nacional de Formação dos Profissionais da Educação Básica. Brasília, 2016.

BRZEZINSKI, Iria. Profissão professor: identidade e profissionalização docente. Brasília: Plano Editora, 2002.

CNE/CP - Conselho Nacional de Educação. Resolução CNE/CP N 01/2002. DOU de 09/04/2002. Brasília, DF.

CNE/CP - Conselho Nacional de Educação. Resolução CNE/CP N 02/2002. DOU de 04/03/2002. Brasília, DF.

GATTI, Bernardete A. Formação de Professores no Brasil: características e problemas.Disponível http://www.scielo.br/pdf/es/v31n113/16.pdf, acesso em 14 julho de 2016.

IFPB. Plano de Desenvolvimento Institucional (2015-2019). João Pessoa, 2014.

.Projeto pedagógico do curso de licenciatura em química. João pessoa, 2010.

Projetopedagógico do curso de licenciatura em Matemática. Cajazeiras, 2011.

MACHADO, Lucília R. de Souza. Diferenciais inovadores na formação de professores para a educação profissional. (documento técnico encaminhado à SETEC/MEC). Brasília: MEC/SETEC, 2008. 
MANFREDI, Sílvia M. Educação profissional no Brasil. São Paulo: Cortez, 2002. p. 65-108.

MOURA, Dante Henrique. A Licenciatura nos IFs em busca de uma Identidade. Palestra proferida no Fórum Nacional das Licenciaturas nos Institutos Federais - FONALIFE, Natal, 2010.

QUELUZ, Gilson Leandro. O contexto de surgimento da Escolas de Aprendizes Artífices: sociedade do trabalho, menoridade e ensino-técnico profissional. In: Concepções de Ensino Técnico na República Velha: 1909-1930. Curitiba: Ed. CEFETPR, 2000. p. 17-32.

SOUSA, Aparecida Gasquez; BERALDO, Tânia Maria. Cursos de licenciaturas em ciências naturais nos institutos federais de educação, ciência e tecnologia. In: CONGRESSO NACIONAL DE EDUCAÇÃO, 9, ENCONTRO SUL BRASILEIRO DE PSICOPEDAGOGIA, 3. Anais eletrônicos... Paraná, 2009.

p. 10169-10182.

Disponível em<http://www.pucpr.br/eventos/educere/educere2009/anais/pdf/1920_1102.pdf> Acesso em: 12 ago. 2016. 